Pacific Journal of Mathematics

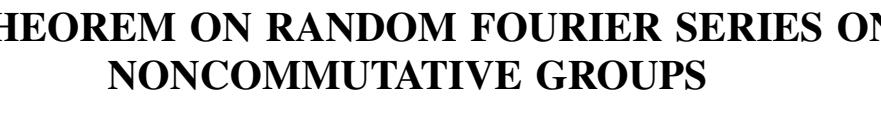




\section{A THEOREM ON RANDOM FOURIER SERIES ON NONCOMMUTATIVE GROUPS}

\section{Alessandro Figà-Talamanca and Daniel Rider}

Let $G$ be a compact group. For $x \in G$ we shall consider a formal Fourier series $\left(^{*}\right) \sum d_{i} \operatorname{Tr}\left(U_{i} A_{i} D_{i}(x)\right)$ where the $D_{i}$ are distinct (non equivalent) irreducible representations of $G$ of degree $d_{i}, U_{i}$ are arbitrary unitary operators and $A_{i}$ fixed linear transformations on the Hilbert space of dimension $d_{i}$ and $T r$ denotes the ordinary trace. We shall prove that $\sum d_{i} \operatorname{Tr}\left(A_{i} A_{i}{ }^{*}\right)<\infty$, provided that $\left.{ }^{*}\right)$ represents a function in $L^{1}(G)$ for all $U=\left\{U_{i}\right\}$ belonging to a set $M$ which has positive Haar measure in the group $\mathbb{S}=\Pi \mathscr{U}\left(d_{i}\right)$, where $\mathscr{U}\left(d_{i}\right)$ is the group of all unitary operators on the $d_{i}$-dimensional space. If we think of $\mathbb{S}$ as a probability space, with respect to its Haar measure, then $(*)$ is a Fourier series with "random coefficients" and the result can be stated in the following way: if $\left(^{*}\right)$ represents, with positive probability, a function in $L^{1}(G)$ then $\sum d_{i} \operatorname{Tr}\left(A_{i} A_{i}^{*}\right)<\infty$. An earlier result of the authors implies then that, under the same hypothesis, $\left(^{*}\right)$ is, with probability one, the Fourier series of a function belonging to $L^{p}(G)$ for every $p<\infty$.

This result is a generalization of a classical result for the unit circle (cf. e.g. [6, 8.14 p. 215]). With the stronger hypothesis that (*) represents an integrable function for every choice of $U=\left\{U_{i}\right\} \in \mathbb{S}$, the theorem was proved by Helgason [5]. His proof, as the proof of [2, Th. 4], exploited the "lacunary" properties of a subset of the irreducible representations of \&. Or, from another point of view, it was based on the fact that certain functions defined on 85 share some of the properties of Rademacher series (the reader should compare [6, 8.4, p. 213] with [5, (4.12), p. 279] and [2, Lemma 3]). In effect, to obtain the main result of this paper we prove first that yet another property of Rademacher series $[6,8.3, \mathrm{p} .213]$ is shared by their noncommutative analogue (cf. Lemma 1, below). To conclude the proof it is then necessary to apply some recent results of Edwards and Hewitt [1] on methods of pointwise summability for arbitrary compact groups.

1. Preliminaries. Let $\mathbb{B}=\prod_{i \in I} \mathscr{U}\left(d_{i}\right)$. The projection $D_{i}(V)$ of $V \in \mathbb{S}$ into $\mathscr{U}\left(d_{i}\right)$ is clearly an irreducible unitary representation. $\bar{D}_{i}$ will denote the representation conjugate to $D_{i}$. We shall consider functions of $L^{2}(\mathrm{~S})$ of the form

$$
F(V)=\sum_{i \in I} d_{i} \operatorname{Tr}\left(A_{i} D_{i}(V)\right)
$$


where $A_{i}$ is a $d_{i} \times d_{i}$ matrix. The element of Haar measure on (8) will be denoted by $d V$. The Schur-Peter-Weyl formula yields

$$
\int|F(V)|^{2} d V=\sum_{i} d_{i} \operatorname{Tr}\left(A_{i} A_{i}^{*}\right) .
$$

LEMma 1. Given a set $M \subset \$ S$ of positive Haar measure $m(M)$ and $\varepsilon>0$, there exists a finite set $I_{0} \subset I$ (depending on $M$ and $\varepsilon$ ) such that if

$$
F(V)=\sum_{i \notin I_{0}} d_{i} \operatorname{Tr}\left(A_{i} D_{i}(V)\right) \in L^{2}(\mathbb{S})
$$

then

$$
m(M) \int|F(V)|^{2} d V \leqq(1+\varepsilon) \int_{M}|F(V)|^{2} d V
$$

Proof. We first make the following observations.

(a) If $d_{i} \geqq 2$ then $D_{i} \otimes \bar{D}_{i}$ decomposes into two irreducible components. One is the identity; the other will be denoted by $D_{i, i}$.

(b) If $i \neq j$ then $D_{i} \otimes \bar{D}_{j}=D_{i, j}$ is irreducible.

(c) $D_{i, j}$ and $D_{m, n}$ are equivalent if and only if $i=m$ and $j=n$.

(a) and (b) follow directly from the remarks of Helgason [4, p. 788]. He notes that, for $d_{i} \geqq 2, D_{i} \otimes D_{i}$ decomposes into two irreducible components and that, for $i \neq j, D_{i} \otimes D_{j}$ is irreducible. But the number of components of $D_{i} \otimes D_{j}$ is

$$
\int_{\mathscr{S}}\left|\operatorname{Tr}\left(D_{i}(V)\right) \operatorname{Tr}\left(D_{j}(V)\right)\right|^{2} d V
$$

which is also the number of components of $D_{i} \otimes \bar{D}_{j}$. Since $D_{i}$ is irreducible the identity appears once as a component of $D_{i} \otimes \bar{D}_{i}$.

Now $\operatorname{Tr}\left(D_{i, j}(V)\right)=\operatorname{Tr}\left(D_{i}(V)\right) \overline{\operatorname{Tr}\left(D_{j}(V)\right)}-\delta_{i j}$ where $\delta_{i j}$ is the Kronecker delta. It follows that if $D_{i, j}$ and $D_{m, n}$ are equivalent then

$$
\begin{aligned}
1 & =\int \operatorname{Tr}\left(D_{i, j}(V)\right) \overline{\operatorname{Tr}\left(D_{m, n}(V)\right)} d V \\
& =\int \operatorname{Tr}\left(D_{i}(V)\right) \overline{\operatorname{Tr}\left(D_{j}(V)\right) \operatorname{Tr}\left(D_{m}(V)\right)} \operatorname{Tr}\left(D_{n}(V)\right) d V-\delta_{i j} \delta_{m n} .
\end{aligned}
$$

This is possible only if the second integral is not zero. But, by the invariance of $d V$, this implies $i=j$ and $m=n$ or $i=m$ and $j=n$. Now if $i=j, m=n$, but $i \neq m$ then (by (b)) $D_{i} \otimes \bar{D}_{m}=D_{j} \otimes \bar{D}_{n}$ is irreducible, and the second integral is one. But since $\delta_{i j} \delta_{m n}=1$ this is not possible. Thus $i=m$ and $j=n$ so that (c) is proved.

Since $\operatorname{Tr}\left(A_{i} D_{i}(V)\right)$ and $\overline{\operatorname{Tr}\left(A_{j} D_{j}(V)\right)}$ lie in the invariant subspaces generated by $\operatorname{Tr}\left(D_{i}(V)\right)$ and $\operatorname{Tr}\left(\bar{D}_{j}(V)\right)$ it follows from (a), (b) and 
(1.1) that

$$
\operatorname{Tr}\left(A_{i} D_{i}(V)\right) \overline{\operatorname{Tr}\left(A_{j} D_{j}(V)\right)}=\frac{\delta_{i j}}{d_{i}} \operatorname{Tr}\left(A_{i} A_{i}^{*}\right)+\operatorname{Tr}\left(A_{i, j} D_{i, j}(V)\right)
$$

where $d_{i, j}$ is the degree of $D_{i, j}$ and $A_{i, j}$ is a $d_{i, j} \times d_{i, j}$ matrix.

If $M$ is a subset of $(B)$ of positive measure then its characteristic function, $\varphi_{M}$, has an expansion in $L^{2}(\mathbb{S})$

$$
\varphi_{M}(V)=\sum_{i, j} d_{i, j} \operatorname{Tr}\left(B_{i, j} D_{i, j}(V)\right)+\underset{\alpha}{+} \sum d(\alpha) \operatorname{Tr}\left(B_{\alpha} D_{\alpha}(V)\right)
$$

the second sum is over the representations of $\$ 5$ which are not equivalent to any $D_{i, j}$.

From the Schur-Peter-Weyl formula we obtain

$$
\sum_{i, j} d_{i, j} \operatorname{Tr}\left(B_{i, j} B_{i, j}^{*}\right) \leqq m(M) .
$$

Given $\varepsilon>0$ it follows from the above and (c) that there is a finite set $I_{0} \subset I$ such that

$$
\sum_{i, j \notin I_{0}} d_{i, j} \operatorname{Tr}\left(B_{i, j} B_{i, j}^{*}\right)<\varepsilon^{2} .
$$

Suppose $F(V)=\sum_{i \notin I_{0}} d_{i} \operatorname{Tr}\left(A_{i} D_{i}(V)\right) \in L^{2}(\mathbb{S})$. From

(1.2) and (1.3) it follows that

$$
\begin{aligned}
& \int_{M}|F(V)|^{2} d V=\sum_{i \notin I_{0}} d_{i} \operatorname{Tr}\left(A_{i} A_{i}^{*}\right) m(M) \\
& +\sum_{i, j \notin I_{0}} d_{i} d_{j} d_{i, j} \int \operatorname{Tr}\left(A_{i, j} D_{i, j}(V)\right) \operatorname{Tr}\left(B_{j, i} D_{j, i}(V)\right) .
\end{aligned}
$$

From (1.2) and Holder's inequality it follows that the integrals in the second sum of (1.5) are bounded by

$$
\left[\int\left|\operatorname{Tr}\left(B_{j, i} D_{j, i}(V)\right)\right|^{2}\right]^{1 / 2}\left[\int\left|\operatorname{Tr}\left(A_{i} D_{i}(V)\right)\right|^{4} \cdot \int\left|\operatorname{Tr}\left(A_{j} D_{j}(V)\right)\right|^{4}\right]^{1 / 4} \cdot
$$

But by [2, Lemma 1] there is a finite constant $B$ such that

$$
\int\left|\operatorname{Tr}\left(A_{i} D_{i}(V)\right)\right|^{4} \leqq \frac{B^{2}}{d_{i}^{2}}\left[\operatorname{Tr}\left(A_{i} A_{i}^{*}\right)\right]^{2} .
$$

Hence the second summand of (1.5) is majorized by

$$
\begin{aligned}
& B \sum_{i, j \notin I_{0}}\left[d_{i, j} \operatorname{Tr}\left(B_{j, i} B_{j, i}^{*}\right) d_{i} \operatorname{Tr}\left(A_{i} A_{i}^{*}\right) d_{j} \operatorname{Tr}\left(A_{j} A_{j}^{*}\right)\right]^{1 / 2} \\
& \leqq B\left[\sum_{i, j \notin I_{0}} d_{i, j} \operatorname{Tr}\left(B_{i, j} B_{i, j}^{*}\right)\right]^{1 / 2} \sum_{i \notin I_{0}} d_{i} \operatorname{Tr}\left(A_{i} A_{i}^{*}\right)
\end{aligned}
$$

which by (1.4) is bounded by 


$$
B \varepsilon \int|F(V)|^{2} d V
$$

Hence we have

$$
\left.\left|\int\right| F(V)\right|^{2} d V-\left.\int|F(V)|^{2} d V \cdot m(M)\left|\leqq B \varepsilon \int\right| F(V)\right|^{2} d V
$$

which proves the lemma.

We now introduce some terminology which will be used in the rest of the paper and state the result of Hewitt and Edwards which will be used in the proof of the main theorem. Let $G$ be an arbitrary compact group and $\Gamma$ the set of equivalence classes of irreducible unitary representations of $G$. If $\gamma \in \Gamma$ we let $D_{\gamma}$ be a representative of the class $\gamma$ and $d_{\gamma}$ be the degree of $\gamma$. For $f \in L^{1}(G)$ we let

$$
\hat{f}\left(D_{\gamma}\right)=\int_{\theta} f(x) D_{\gamma}\left(x^{-1}\right) d x
$$

so that the Fourier series of $f$ is written as $\sum_{\gamma \in \Gamma} d_{\gamma} \operatorname{Tr}\left(\hat{f}\left(D_{\gamma}\right) D_{\gamma}(x)\right)$.

LEMma 2. (Edwards and Hewitt). Let $G$ be a compact group and $Y=\left\{\gamma_{j}\right\}_{j=1}^{\infty}$ be a countable subset of $\Gamma$. Let $D_{j}$ be a representative of the class $\gamma_{j}$. Then there exist complex numbers $\alpha_{m, n, j}$ such that

(i) for fixed $m$ and $n, \alpha_{m, n, j}=0$ except for finitely many $j$ 's.

(ii) if $f \in L^{1}(G)$ and $\hat{f}\left(D_{\gamma}\right)=0$ for $\gamma \notin Y$

$$
\lim _{m} \lim _{n} \sum_{j} \alpha_{m, n, j} \operatorname{Tr}\left(f\left(D_{j}\right) D_{j}(x)\right)=f(x)
$$

almost everywhere with respect to the Haar measure on $G$.

Proof. [1, 5.11, p. 216 and 3.5, p. 199]. It should be noted that the lemma implies that $\lim _{m} \lim _{n} \alpha_{m, n, j}=1$ for each $j$.

2. The main theorem. We consider now the formal Fourier series

$$
\sum d_{\gamma} \operatorname{Tr}\left(U_{\gamma} A_{\gamma} D_{\gamma}(x)\right)
$$

and we prove:

THEOREM 3. Suppose that there exists a set $M$ of positive Haar measure in $\mathbb{S}=\Pi_{\gamma \in \Gamma} \mathscr{U}\left(d_{\gamma}\right)$ such that (2.1) is the Fourier series of an integrable function for $\left\{U_{\gamma}\right\}=U \in M$, then $\sum d_{\gamma} \operatorname{Tr}\left(A_{\gamma} A_{\gamma}^{*}\right)<\infty$.

Proof. Since for some choice of $\left\{U_{\gamma}\right\}$ (2.1) represents a function of $L^{1}(G), A_{\gamma}=0$ except for $\gamma$ belonging to a countable set $Y=\left\{\gamma_{j}\right\}$. 
Therefore we can rewrite (2.1) as $\sum_{1}^{\infty} d_{j} \operatorname{Tr}\left(U_{j} A_{j} D_{j}(x)\right)$. We define for $U \in M$ and $x \in G, f(x, U)=\sum d_{j} \operatorname{Tr}\left(U_{j} A_{j} D_{j}(x)\right)$. Then for every $U \in M, \int_{a}|f(x, U)| d x<\infty$. Therefore there exists a set of positive measure $M_{1} \subset M$ and a number $B$ such that $\int_{\theta}|f(x, U)| d x<B$ for $U \in M_{1}$. Thus $\int_{M_{1}} \int_{G}|f(x, U)| d x d U<\infty$ and $f(x, U)$ is an integrable function on $G \times M_{1}$.

Let $\alpha_{m, n, j}$ be as in Lemma 2. Define

$$
f_{m, n}(x, U)=\sum d_{j} \alpha_{m, n, j} \operatorname{Tr}\left(U_{j} A_{j} D_{j}(x)\right)
$$

and

$$
f_{m}(x, U)=\lim _{n} f_{m, n}(x, U) .
$$

Lemma 2 implies that $f_{m}(x, U)$ exists almost everywhere in $G \times M$ and $\lim _{m} f_{m}(x, U)=f(x, U)$ almost everywhere in $G \times M_{1}$. Now there exists a set of positive measure $P \subset G \times M_{1}$ such that

$$
\sup _{(x, U) \in P}|f(x, U)|<\infty, \lim _{n} \sup _{(x, U) \in P}\left|f_{m, n}(x, U)-f_{m}(x, U)\right|=0
$$

and

$$
\lim _{m} \sup _{(x, U) \in P}\left|f_{m}(x, U)-f(x, U)\right|=0 .
$$

Indeed as $f(x, U)$ is integrable, it is bounded on a subset of positive measure of $G \times M_{1}$. Furthermore, given $\delta>0$, Egoroff's theorem [2, p. 88] implies that $\lim _{n} f_{m, n}(x, U)=f_{m}(x, U)$ uniformly for $(x, U)$ outside a set of measure less that $\delta / 2^{n}$ and $\lim _{n} f_{n}(x, U)=f(x, U)$ uniformly outside a set of measure $\delta$. As $\delta$ can be arbitrarily small we can find a set $P$ of positive measure satisfying our requirements.

Now let $C$ be such that $\left|f_{m}(x, U)\right| \leqq C$ and $|f(x, U)| \leqq C$ for $(x, U) \in P$. We let $\alpha_{m j}=\lim _{n} \alpha_{m, n, j}$ and we define a set of positive integers $n_{m}$ such that for $j=1, \cdots, m,\left|\alpha_{m, n_{m}, j}-\alpha_{m j}\right|<(1 / m)$ and $\left|f_{m}(x, U)-f_{m, n_{m}}(x, U)\right|<1$ for $(x, U) \in P$. We let $\beta_{m j}=\alpha_{m, n_{m}, j}$ and $g_{m}(x, U)=f_{m, n}(x, U)$. Then $\lim \beta_{m j}=1$ for each $j$ and $\left|g_{m}(x, U)\right| \leqq$ $C+1=C^{\prime}$. We notice that $g_{m}(x, U)=\sum_{j} d_{j} \beta_{m j} \operatorname{Tr}\left(U_{j} A_{j} D_{j}(x)\right)$ where the sum only extends over a finite number of $j$ 's. Since the measure of $P$ is positive, Fubini's theorem implies that for some $x \in G$ the set $P_{x}=\{U \in \mathbb{B}:(x, U) \in P\}$ has positive measure. We fix such an $x$ and consider the functions $g_{m}(x, U)$ as functions defined on $\mathbb{B}$.

With reference to the subset $P_{x}$ of $B$ and $\varepsilon=1$ we can find a finite subset $F \subset \Gamma$ which satisfies the conclusion of Lemma 1. If we let $g_{m}^{\prime}(x, U)=\sum_{\gamma, \notin F} d_{j} \beta_{m j} \operatorname{Tr}\left(U_{j} A_{j} D_{j}(x)\right)$ then $\left|g_{m}^{\prime}(x, U)\right| \leqq C^{\prime \prime}$ for $U \in P_{x}$ and an application of Lemma 1 yields 


$$
\begin{aligned}
\sum d_{j}\left|\beta_{m j}\right|^{2} \operatorname{Tr}\left(A_{j} A_{j}^{*}\right)= & \sum_{\gamma_{j} \in F} d_{j}\left|\beta_{m j}\right|^{2} \operatorname{Tr}\left(A_{j} A_{j}^{*}\right) \\
& +\sum_{\gamma_{j} \notin F} d_{j}\left|\beta_{m j}\right|^{2} \operatorname{Tr}\left(A_{j} A_{j}^{*}\right) \\
\leqq & \sum_{\gamma_{j} \in F} d_{j}\left|\beta_{m j}\right|^{2} \operatorname{Tr}\left(A_{j} A_{j}^{*}\right) \\
& +\frac{2}{m\left(P_{x}\right)} \int_{P_{x}}\left|g_{m}^{\prime}(x, U)\right|^{2} d U \\
\leqq & \sum_{\gamma_{j} \in F} d_{j}\left|\beta_{m j}\right|^{2} \operatorname{Tr}\left(A_{j} A_{j}^{*}\right)+2\left(C^{\prime \prime}\right)^{2}<\omega .
\end{aligned}
$$

Taking limits as $m \rightarrow \infty$ one finds that

$$
\sum d_{j} \operatorname{Tr}\left(A_{j} A_{j}^{*}\right) \leqq \sum_{\gamma_{j} \in F} d_{j} \operatorname{Tr}\left(A_{j} A_{j}^{*}\right)+2\left(C^{\prime \prime}\right)^{2}<\infty
$$

COROLLARY 4. If the formal Fourier series (2.1) satisfies the hypothesis of Theorem 3, then for almost every $U \in \mathbb{B}$ it is the Fourier series of a function in $\bigcap_{p<\infty} L^{p}(G)$.

Proof. Since $\sum d_{j} \operatorname{Tr}\left(A_{j} A_{j}^{*}\right)<\infty,[2$, Th. 4] implies that

$$
\sum d_{j} \operatorname{Tr}\left(U_{j} A_{j} D_{j}(x)\right) \in L^{p}
$$

except for $U \in N_{p}$ with $m\left(N_{p}\right)=0$. 'Letting $p=1,2, \cdots$ and $N=\bigcup_{p=1}^{\infty} N_{p}$, one has $m(N)=0$ and the conclusion follows.

REMARK. To obtain the conclusion of Theorem 3 it is enough to assume that (2.1) represents a Fourier-Stieltjes series for $U \in M$, $m(M)>0$. Indeed by Theorem 3 , one has under this hypothesis a bounded regular measure $\mu$, with $\mu\left(D_{\gamma}\right)=U_{\gamma} A_{\gamma}$, satisfying $f * \mu \in L^{2}(G)$ for every $f \in L^{1}(G)$. The theorem of Helgason [5, Th. A] implies then that $d \mu=f d x$ with $f \in L^{2}(G)$.

\section{REFERENCES}

1. R. E. Edwards and E. Hewitt, Pointwise limits for sequences of convolution operators, Acta Math. 133 (1965), 181-217.

2. A. Figà-Talamanca and D. Rider, A theorem of Littlewood and lacunary series for compact groups, Pacific J. Math. 16 (1966), 505-514.

3. P. R. Halmos, Measure Theory, Van Nostrand, Princeton, New Jersey, 1950.

4. S. Helgason, Lacunary Fourier series on noncommutative groups, Proc. Amer. Math. Soc. 9 (1958), 782-790.

5. Topologies of group algebras and a theorem of Littlewood, Trans. Amer. Math. Soc. 86 (1957), 269-283.

6. A. Zygmund, Trigonometric Series, Vol. I, Cambridge University Press, Cambridge, 1959.

Received March 15, 1966. Research sponsored in part by the Air Force Office of Scientific Research, Grant A-AFOSR 335-63. 


\section{PACIFIC JOURNAL OF MATHEMATICS}

\section{EDITORS}

\section{H. SAMELSON}

Stanford University

Stanford, California

\author{
J. P. JANS \\ University of Washington \\ Seattle, Washington 98105
}

\section{J. DuGUNDJI}

University of Southern California

Los Angeles, California 90007

RichaRd ARENS

University of California

Los Angeles, California 90024

\section{ASSOCIATE EDITORS}

E. F. BECKENBACH
B. H. NeUManN

F. WOLF

K. YOSIDA

\section{SUPPORTING INSTITUTIONS}

UNIVERSITY OF BRITISH COLUMBIA

CALIFORNIA INSTITUTE OF TECHNOLOGY

UNIVERSITY OF CALIFORNIA

MONTANA STATE UNIVERSITY

UNIVERSITY OF NEVADA

NEW MEXICO STATE UNIVERSITY

OREGON STATE UNIVERSITY

UNIVERSITY OF OREGON

OSAKA UNIVERSITY

UNIVERSITY OF SOUTHERN CALIFORNIA
STANFORD UNIVERSITY

UNIVERSITY OF TOKYO

UNIVERSITY OF UTAH

WASHINGTON STATE UNIVERSITY

UNIVERSITY OF WASHINGTON

AMERICAN MATHEMATICAL SOCIETY

CHEVRON RESEARCH CORPORATION

TRW SYSTEMS

NAVAL ORDNANCE TEST STATION

Mathematical papers intended for publication in the Pacific Journal of Mathematics should be typewritten (double spaced). The first paragraph or two must be capable of being used separately as a synopsis of the entire paper. It should not contain references to the bibliography. Manuscripts may be sent to any one of the four editors. All other communications to the editors should be addressed to the managing editor, Richard Arens at the University of California, Los Angeles, California 90024.

50 reprints per author of each article are furnished free of charge; additional copies may be obtained at cost in multiples of 50 .

The Pacific Journal of Mathematics is published monthly. Effective with Volume 16 the price per volume ( 3 numbers) is $\$ 8.00$; single issues, $\$ 3.00$. Special price for current issues to individual faculty members of supporting institutions and to individual members of the American Mathematical Society: $\$ 4.00$ per volume; single issues $\$ 1.50$. Back numbers are available.

Subscriptions, orders for back numbers, and changes of address should be sent to Pacific Journal of Mathematics, 103 Highland Boulevard, Berkeley 8, California.

Printed at Kokusai Bunken Insatsusha (International Academic Printing Co., Ltd.), No. 6, 2-chome, Fujimi-cho, Chiyoda-ku, Tokyo, Japan.

PUBLISHED BY PACIFIC JOURNAL OF MATHEMATICS, A NON-PROFIT CORPORATION

The Supporting Institutions listed above contribute to the cost of publication of this Journal, but they are not owners or publishers and have no responsibility for its content or policies. 


\section{Pacific Journal of Mathematics}

\section{Vol. 21, No. $3 \quad$ BadMonth, 1967}

Richard Allen Askey, A transplantation theorem for Jacobi coefficients . . . 393

Raymond Balbes, Projective and injective distributive lattices .......... 405

Raymond Balbes and Alfred Horn, Order sums of distributive lattices . . . . 421

Donald Charles Benson, Nonconstant locally recurrent functions ........ 437

Allen Richard Bernstein, Invariant subspaces of polynomially compact operators on Banach space ............................... 445

Robert F. Brown, Fixed points and fibre ................... 465

David Geoffrey Cantor, On the Stone-Weierstrass approximation theorem for valued fields ................................ 473

James Walton England, Stability in topological dynamics .............. 479

Alessandro Figà-Talamanca and Daniel Rider, A theorem on random

Fourier series on noncommutative groups.................. 487

Sav Roman Harasymiv, A note of dilations in $L^{p} \ldots \ldots \ldots \ldots \ldots \ldots . \ldots 493$

J. G. Kalbfleisch, A uniqueness theorem for edge-chromatic graphs ....... 503

Richard Paul Kelisky and Theodore Joseph Rivlin, Iterates of Bernstein polynomials .................................... 511

D. G. Larman, On the union of two starshaped sets ............... 521

Henry B. Mann, Josephine Mitchell and Lowell Schoenfeld, Properties of differential forms in $n$ real variables ...................... 525

John W. Moon and Leo Moser, Generating oriented graphs by means of team comparisons .

Veikko Nevanlinna, A refinement of Selberg's asymptotic equation ...

Ulrich Oberst, Relative satellites and derived functors of functors with additive domain ..............................

John Vincent Ryff, On Muirhead's theorem...............

Carroll O. Wilde and Klaus G. Witz, Invariant means and the Stone-Čech compactification 